\title{
Self-Interest, Automaticity, and the Psychology of Conflict of Interest
}

\author{
Don A. Moore ${ }^{1,2}$ and George Loewenstein ${ }^{1}$
}

This paper argues that self-interest and concern for others influence behavior through different cognitive systems. Self-interest is automatic, viscerally compelling, and often unconscious. Understanding one's ethical and professional obligations to others, in contrast, often involves a more thoughtful process. The automatic nature of self-interest gives it a primal power to influence judgment and make it difficult for people to understand its influence on their judgment, let alone eradicate its influence. This dual-process view offers new insights into how conflict of interest operate and it suggests some new avenues for addressing them or limiting some of their greatest dangers.

KEY WORDS: conflict of interest; dual process; self-interest; professionalism.

Conflicts of interest are at the heart of many of the recent scandals that have shaken the U.S. economy. Conflicts of interest like those between a firm's managers, its shareholders, and its auditors have existed for some time. Why is it that they have recently resulted in such colossal business failures? ${ }^{3}$ A common theme in many discussions of recent scandals is that problems have followed changes in professional mindset. In earlier times, auditors saw their task as that of a detective- to ferret out errors and inconsistencies in the client's accounts. For example, Arthur Andersen, in his early days as an auditor, discovered that a large client of his was inflating profit reports by incorrectly classifying routine expenses as capital investments. When the client demanded that Andersen provide a clean audit report,

${ }^{1}$ Carnegie Mellon University, Pittsburgh, Pennsylvania.

${ }^{2}$ All correspondence should be addressed to Don A. Moore, Carnegie Mellon University, 5000 Forbes Avenue, Pittsburgh, Pennsylvania 15213; e-mail: dmoore@cmu.edu

${ }^{3}$ Evidence of the increase in not only the magnitude but also frequency of scandals, earnings restatements have grown dramatically in recent years. Averaging 28 per year over the 20 years between 1977 through 1997, they have averaged 160 per year in the 5 years between 1998 through 2002 (Stock, 2003). 
Andersen replied he would not do so for all the money in the city of Chicago (McRoberts, 2002). Over the years, however, the unimpeachable reputation that Arthur Andersen worked so hard to cultivate at the firm that bore his name began to falter. The ethics watchdogs at Andersen's Professional Standards Group saw their influence wane while the influence of the firm's salesmen increased. New hires were told that Andersen served as a business partner to its clients, seeking to help them become successful in every aspect of their businesses. Indeed, shortly before the collapse of the Enron Corporation, Andersen had been preparing a campaign advertising its new "integrated audit" approach, with Enron as the example (Dugan et al., 2002). Andersen's "mindset" with regard to what the task of auditing was all about, it seems, underwent a radical evolution.

What, exactly does "mindset" mean? Why should it matter? To make sense of the concept, and understand its relevance to conflict of interest, it is useful to map it onto a commonplace and long-standing distinction drawn by psychologists between two different modes of information processing that characterize human cognition. Although there are differences between specific versions of such "dual process" perspectives, the most common dichotomy distinguishes between (a) processes that are relatively effortless and unconscious, and, (b) processes that are more analytical, but also more effortful. We refer to these as "automatic" and "controlled" processes, respectively, borrowing terminology first proposed by Schneider and Shifrin (1977). Research has shown that automatic and controlled processes often act in concert to produce judgments and decisions, but in certain predictable situations, they can come into conflict.

Much as dual-process models involve two different modes of thought, conflicts of interest involve two disparate motives that professionals often confront simultaneously: professional responsibilities and personal interests. As is true for automatic and controlled processes, these motives do not always clash; professional responsibilities and self-interest often coincide and reinforce one another. Many of the choices made by physicians, lawyers, and financial advisors are straightforward because the same outcomes may be beneficial to both the client and themselves. However, professional responsibilities and self-interest, like automatic and controlled processes, do come into conflict with one another. For example, physicians get paid more when they provide more treatments whether or not those treatments benefit their patients, attorneys often get paid more when their clients are involved in more protracted conflicts, and real estate agents get paid more when their buyers find houses quickly and pay more for them.

Our basic argument is that, when professional responsibilities clash with self-interest, the two motives tend to be processed differently: Self-interest exerts a more automatic influence than do professional responsibilities, which are more likely to be invoked through controlled processing. Since automatic processing tends to occur outside of conscious awareness, its influence on judgment and decision making is difficult to eliminate or completely correct. The consequence 
Table I. Characteristics of Automatic and Controlled Mental Processes

\begin{tabular}{ll}
\hline \multicolumn{1}{c}{ Automatic processes } & \multicolumn{1}{c}{ Controlled processes } \\
\hline Fast (due to parallel processing) & Slow (due to serial processing) \\
Effortless & Effortful \\
Involuntary & Voluntary \\
Inscrutable (not accessible to introspection) & Accessible to introspection \\
\hline
\end{tabular}

of this differential processing is that self-interest often prevails, even when decision makers consciously attempt to comply with the ethical mandates of their profession.

In what follows, we begin with a brief introduction to dual-process research. Then we attempt to substantiate our claim that self-interest and professional responsibilities are processed differently. Finally, we show that taking account of these two disparate modes of information processing can help to inform our understanding of how people deal with conflicts of interest and the policies that are likely to be effective in dealing with them.

\section{DUAL-PROCESS MODELS}

Although specific dual-process models differ not only in labels, ${ }^{4}$ but also in substance, they share important commonalities. A synthesis of dichotomies proposed by different researchers would result in a categorization of characteristics like that in Table I.

Automatic processes are epitomized by the neural processing of vision, which embodies all of the features listed in the left column of Table I. Vision involves numerous parallel processes-e.g., edge and pattern recognition and retrieval of information from memory. Vision is also largely unaccompanied by any feeling of subjective effort, and does not detract from other similar processes (e.g., it is equally easy to speak with one's eyes open or shut, and likewise equally easy to see when one is or is not talking). Vision is also involuntary; except by blocking one's visual field, it is impossible to choose not to see. The cognitive processes that give rise to vision are also almost totally inscrutable. Most people, if asked to explain how it is that they can "see" whatever is in their visual field, would have a great deal of trouble answering the question. For example, people are generally not able to offer articulate insight into how their brains solve visual problems such as depth perception or face recognition.

\footnotetext{
${ }^{4}$ For example, Schneider and Shiffrin (1977) distinguish between automatic and controlled processes, Chaiken and coauthors (see Chaiken and Trope, 1999; Chen, Shechter, and Chaiken, 1996) between systematic and heuristic systems, Epstein (1990) between rational and experiential systems, and Lieberman et al. (2002) draw similar distinctions.
} 
Controlled processing seems to be largely centered in a relatively small region of the brain, the prefrontal cortex, that is more developed in humans than in other animals. Controlled processing is epitomized by the types of systematic cost-benefit analyses that decision theorists often erroneously assume to be the core process of decision making. Controlled processes are slow because they are characterized by step-by-step symbol-manipulation. They are often associated with a subjective feeling of effort, and they can produce fatigue over time. These processes are voluntary in the sense that they can be induced deliberately and, to an extent, they can be deliberately curtailed. While introspective access is by no means perfect, we do have a much greater ability to introspect about controlled processes than about automatic processes-e.g., we can often articulate the various costs and benefits that went into a deliberate decision, as opposed to automatic judgments.

\section{AFFECT AND AUTOMATICITY}

When it comes to decision making, an additional, albeit somewhat less sharp, distinction is that between immediate affect and anticipated affect regarding decision outcomes (Loewenstein et al., 2001; Loewenstein and Lerner, 2002). Automatic processes tend to invoke immediate affect, whereas controlled processes tend to deal with anticipated affect. For example, when choosing between restaurants, one may have an immediate affective response to the thought of Chinese food, but one might also deliberately attempt to predict how much one will enjoy eating Chinese food. This anticipated affect would entail thoughtful prediction of one's response to the food.

As the restaurant example suggests, automatic and controlled processes, and immediate and expected affect, often work in concert to produce judgments and decisions. If you like Chinese food, your immediate and anticipated affective responses will both be positive. However, automatic judgments and immediate affect can come into conflict with controlled judgments and anticipated affect, and when they do, automatic processing and immediate affect often prevail. As Rita Carter writes in Mapping the Mind, "where [conscious] thought conflicts with emotions, the latter is designed by the neural circuitry in our brains to win."

In one stylized demonstration of such divergence, and of the dominance of automatic, emotional, processing, Denes-Raj and Epstein (1994) gave experimental subjects a choice between betting on drawing a red jellybean out of one jar that contained 7 red jellybeans out of 100 and another that contained 1 red jellybean out of 10. Although they reported that they "knew" that the objective probability was higher in the second jar, they nevertheless were more likely to bet on the first jar. Denes-Raj and Epstein posited that the controlled system, which they called the "rational" system, conformed to the rules of probability while the more automatic, 
"experiential" system was swayed by the raw number of red beans in the first jar. Automatic processes tends to dominate, in part because they tend to be "first on the scene," with controlled processes acting as an override. LeDoux (1996), for example, has shown that there are direct neural projections from sensory organs to the amygdala - a unit of the brain that is closely connected to the processing of fear-that do not go through the cortex. This finding is important because it demonstrates that it is possible to have an immediate emotional reaction to, for example, a noise, before one can even identify what the noise is.

Controlled processes can override automatic processes; indeed this is probably their main function. However, controlled processes are severely constrained, in part due to their serial nature, so their ability to override automatic processes is commensurately limited. Studies show that when mental capacity is constrained because people are under cognitive load, it is harder for them to engage in reflection and correction of automatic judgments (Gilbert et al., 1988a,b; Gilbert, Krull, and Malone, 1990). Similar effects have also been shown for decision making, including situations involving self-control. For example, in research reported in a paper titled "Heart and Mind in Conflict: The Interplay of Affect and Cognition," Shiv and Fedorikhin (1999) had subjects memorize either a two-digit number or a seven-digit number and then walk from one room to another. On the way they were asked to stop at a station where they were presented with a choice between a piece of cake or a bowl of fruit salad. Subjects in the low load (two-digit) condition were much more likely to choose the fruit salad than those in the high load (seven-digit) condition. Those under high cognitive load, it seems, could not muster the mental resources necessary to override the initial automatic impulse.

The dominance of automatic processes stems not only from their tendency to be first on the scene, but also from the powerful influence they exert on controlled processes (Bargh, 1989; Epstein, 1994; Epstein et al., 1992). Research on information processing has identified a number of ways in which automatic judgments and immediate affect can influence controlled processing. First, one's immediate affective state has a powerful effect on information retrieval from memory. Studies of "mood-dependent memory" (Bower, 1981) show that sad people tend to retrieve more sad memories, whereas happy people tend to retrieve more happy memories. Second, information inconsistent with automatic judgments tends to be subject to an additional level of scrutiny and is therefore less likely to be accepted as true. Research on confirmatory information processing shows that people assimilate new information through the perceptual lens of their existing beliefs, in many cases bending facts to fit beliefs rather than vice versa (Kunda, 1990; Most et al., 2001). Likewise, research on motivational biases demonstrates that desires can powerfully distort information processing. As expressed by Gilovich (1991), when people want to believe something, they adopt the implicit attitude "Can I believe it?" whereas when they do not want to believe it their attitude is "Must I believe it?" 
In sum, contrary to the common view both among lay people and social scientists that decisions are made by weighing costs and benefits, the reality is that many decisions are made on the basis of impulse and intuition. This is not to say that conscious deliberation is not important-it is. However, it is often relegated to the role of rationalizing and justifying decisions that have been made for other reasons. Recent research on automatic goal activation has shown that goals can be activated, pursued, and fulfilled without people being consciously aware of the goal at all (Bargh et al., 2001; Bargh and Chartrand, 1999; Chartrand and Bargh, 1996). And Haidt (2001) has shown that, while people tend to think that their moral judgments are backed by some kind of logic, most moral judgments in fact result from "quick, automatic, evaluations," with explicit moral reasoning playing a largely secondary role.

\section{DETERMINANTS OF AUTOMATIC AND CONTROLLED PROCESSING}

The research just reviewed shows that information processed automatically is likely to take precedence over information processed in a controlled fashion. What, then, determines what type of processing will be applied to a particular task or decision?

Perhaps the most basic regularity is that controlled processing tends to be evoked when we encounter new tasks or unexpected information. The novelty or unfamiliarity of a task serves as a cue that our established routines may not work and that more explicit analysis could be helpful. Because controlled processing is constrained, the brain is constantly attempting to shift tasks from controlled to automatic processing. The first time you ride a bike, dance Salsa, or play chess, you will tend to engage the task with controlled processes. However, as you gain familiarity, you will tend to automate the underlying processes, shifting processing from the prefrontal cortex to the motor cortex, the visual cortex, and other automatic systems (Gobet and Simon, 1996). Other research (e.g., Hastie, 1984) has shown that violated expectations lead to an explicit search for an explanation-i.e., interrupt automatic processing. The flip side of the same coin is that rehearsalexecuting the same mental or physical task repeatedly-tends to lead to automatic processing.

A second regularity, already touched upon in the previous section, is that any factors that limit cognitive capacity will tend to favor automatic processing. When people are cognitively busy, they are less able to override automatic reactions. As a result, their automatic responses are more likely to be expressed, even if they are undesirable or inappropriate. For example, busy people are more likely to use negative group stereotypes to judge others. In one study (van Knippenberg et al., 1999), participants read about a crime suspect who either came from a negatively stereotyped group or not. When they were not placed under cognitive load, the 
suspect's Hispanic name did not influence their beliefs about his guilt. However, when they were under cognitive load, suspects named Juan Gutierrez were seen as more likely to be guilty than suspects named John Garner.

\section{DUAL-PROCESS MODELS AND CONFLICT OF INTEREST}

Our central contention is that, in many instances of conflict of interest, selfinterest tends to operate via automatic processes whereas ethical and professional responsibilities operate via controlled processes. We do not believe that this is true for all conflicts of interest, or for all people at all points in time, but that a variety of factors have combined to make this particularly true for many conflicts of interest that currently exist in the United States as well as other capitalist countries.

\section{Evolving Attitudes Toward Self-Interest}

For obvious evolutionary reasons, self-interest tends to be naturally advantaged, in the sense of being processed automatically. The ease with which selfinterest is activated bespeaks the automaticity of the pursuit of self-interest. Nominal and symbolic affiliation with a group is enough to lead people to strenuous advocacy on behalf of, and selective partisan perception with respect to, the group (Cialdini et al., 1976; Hastorf and Cantril, 1954). Role-playing scenarios in which people have no financial incentives elicit egocentrically biased assessments of fairness (Babcock et al., 1995; Thompson and Loewenstein, 1992).

A number of historical developments may have contributed to the validation of the goal of self-interest. The first is the progressive embracing, in our society, of self-interest as a worthy goal. The ascendancy of rational choice perspectives in the social sciences is consistent with this perspective. In a classic case of confusing "is" with "ought," the pervasive idea that people do maximize self-interest has been used to motivate and provide justification for the idea that they should behave in a self-interested fashion (Frank et al., 1993). From books that trumpet the benefits of personal fulfillment (Robbins, 1986) to songs that see loving oneself as "the greatest love of all" (Houston, 2000), self-interest is no longer lumped together with greed as a deadly sin, but is now seen as one of the highest callings of human existence. Numerous social commentators have noted the evolution from John F. Kennedy's instruct to "Ask not what your country can do for you-ask what you can do for your country" to Ronald Reagan's question, "Are you better off than you were four years ago?" Evolutionary theorists and even social psychologists have also contributed to the current ethos. When Milgram (1974) conducted his research documenting people's willingness to administer severe electric shocks at the behest of an experimenter, most people he queried could not believe that they themselves would have behaved in this fashion. Decades later, students raised on Milgram's obedience studies and Zimbardo's Stanford prison experiment (Haney 
et al., 1973) are more likely to accept the lesson that ordinary people can commit unethical acts when the situation leads them to do so. One wonders whether, as a result of this insight, they may feel fewer reservations about behaving in such a fashion themselves. While there are certain benefits of holding a realistic view of human nature, a confusion is with ought can cause such cynicism to be selffulfilling.

If we look at the professions in which conflicts of interest occur, an even more extreme cynicism seems to have taken hold. For example, during the recent stock market boom, stock analysts were found to have issued "buy" recommendations to investors when they were selling the stock themselves. Their own accounts of their behavior, as evidenced in their e-mail messages to colleagues, reveal a shocking level of cynicism. Auditors, whom the law charges with a "complete fidelity to the public trust" and "transcending any employment relationship with the client" (Burger, 1984) were found to have helped clients commit accounting fraud. Even physicians, who remain among the most respected professionals in our society, have acquiesced, for the sake of paid dinners and vacations, to the degradation of their profession by pharmaceutical companies and equipment suppliers (Dana and Loewenstein, 2003). The broad-based acceptance of self-interest undermines norms of professionalism. The broader the acceptance for self-interested behavior, the easier it is for the mind to automate it and the less one has to think about it or even be aware of it.

\section{Slippery Slopes and Escalation of Commitment}

We believe that few professionals begin their careers hoping to indulge in conflicts of interest that allow them to become rich at the expense of their patients, clients, and customers. Instead, ethical lapses are more likely to begin as small decisions where professional principles are ambiguous. Over time, people become more comfortable pushing the boundaries of professional propriety, and they also find themselves having to continue previous courses of action in order to avoid admitting that their earlier actions were improper. In the words of one audit professional, in testimony before the U.S. Securities and Exchange Commission, "Companies don't start off saying we're going to commit accounting fraud, let's go do it. They start off because of a pressure, usually in the quarterly earnings estimates, and so they ... do a few little tweaks here and there that they don't think is really wrong. Then when they have the next quarter, they have to build on that and the next quarter and the next quarter and before they know it, they are in over their heads" (Grant, 2000). Acceptance of unethical behavior can increase with time, much as people are prone to escalate their commitment to previously chosen courses of action (Glover, 2000; Lifton, 2000; Loewenstein, 1996; Staw, 1976; Staw and Ross, 1989). 
As with other habitual behaviors, repetition and rehearsal increase the ability of the mind to automate the task. The more the task is repeated, the easier it becomes to do it again without having to think much about it. Furthermore, such actions can have powerful influences on how we see ourselves and how we perceive the propriety of our actions. Psychological research suggests that people's self-perceptions are remarkably malleable. People tend to observe their own behavior and use it to infer their own values and preferences (Bem, 1972). A classic persuasion study on the foot-in-the-door technique illustrates this point: Freedman and Fraser (1966) had experimenters approach homeowners in California regarding the issue of either safe driving or keeping California beautiful and request that they either sign a petition or place a small sign in the windows of their houses. Two weeks later, a second experimenter asked to place large and unattractive billboards in their yards. Those who had agreed to put signs in their windows two weeks earlier were dramatically more likely to agree to this second, much more imposing request. Why? Evidence suggests it is because earlier compliance influenced the participants' self-perceptions. In Freedman and Fraser's (1966) words: “He may become, in his own eyes, the kind of person who does this sort of thing" (p. 201; see also Lepper, 1973).

\section{Characteristics of Victims}

The immediacy of rewards or personal gratification from serving one's selfinterest enhances their attraction, salience, and power. Also, the statistical or abstract nature of the victims makes it unlikely that sympathy will serve as a countervailing visceral impulse (Small and Loewenstein, 2003). For example, when stock analysts at Morgan Stanley went on television telling people to buy stocks they actually believed to be overvalued, they were misleading investors but helping their firms get business from those clients. The investors who might be hurt by taking the bad advice were an unknown set of potential victims. Research has shown both that people are more likely to help and less willing to hurt specific individuals whom they know than individuals who are unknown and probabilistic (Latane, 1981; Small and Loewenstein, 2003). When auditors consider the possibility of issuing a negative audit report, they are well aware of exactly who it will hurt: the employees and managers at the client firm. The beneficiaries of such honesty are the firm's actual or potential investors, and large and diffuse group, largely unknown to the auditors. But victims of conflicts of interest are not always unknown to professionals. Practicing physicians have more contact with patients than do hospital administrators. When administrators decide to implement a policy that will result in some unnecessary treatments, it is likely to be easier for them to stick by the policy than for the doctors who find themselves prescribing surgeries of questionable benefit to their patients. 


\section{Policy Implications}

Some policy-makers and academics have argued that self-interest will always be the primary motivation and that the way to deal with problems of conflict of interest is to impose large fines and severe punishments for violations of professional obligations so as to increase self-interested motivations to behave ethically. These sorts of punitive approaches are reflected in legal responses to problems of conflict of interest, such as the Sarbanes-Oxley Act of 2002, which increased the potential punishments for those who commit accounting fraud. Such arguments serve to point out that conflicts of interest can be ameliorated by lining up incentives so that they reward desirable behavior-i.e., by eliminating them.

However, there are two problems with legal sanctions as a cure for conflicts of interest. The first is that it is often difficult to obtain accurate measures of behavioral compliance. For example, professors face a conflict of interest in reporting research results. On the one hand, professionalism dictates that they report their results honestly and accurately. On the other hand, tremendous professional rewards go to those with excellent research results. While it is clear that there are negative career consequences for those who are found to have falsified their data, it is unrealistic to think that we will ever be able to detect all those who take liberties reporting the results of their research. Likewise, most auditing fraud is likely to go undetected, and most physicians who overprescribe treatments to their patients will never face negative consequences for doing so. Given the impossibility of implementing effective detection systems, establishing legal penalties powerful enough to counterbalance the potential rewards of unethical behavior is impractical.

The other problem with probabilistic punishment has to do with the differing psychological impacts of immediate-certain and distant-uncertain events. Events known to be certain and near at hand tend to be more psychologically immediate and hence more motivating (Frederick et al., 2002). The rewards of unethical behavior are often immediate and clear, whereas the potential costs depend on being caught, prosecuted, and punished. Research on the effectiveness of punishment as a deterrent to crime shows, consistent with the basic principles of learning, that its deterrent power is severely constrained by its distant and probabilistic nature (McFatter, 1982). Because it is neither swift nor certain, criminal punishment often lacks the psychological vividness and motivational strength that is required to counteract the immediate rewards associated with indulging one's conflicts of interest.

On the other hand, there are reasons to expect that deterrence might be effective if implemented properly. One way in which rule-based deterrence can work is by proscribing certain behaviors and putting them outside the bounds of propriety. Although there are times and places where stopping at a stop sign is unnecessary because there is no one else on the road (including police), people tend to stop anyway because the law tells them to do so. This desired result can backfire, however, 
and the threat of punishment can actually increase the prevalence of the undesired behavior if people view the penalty as simply an economic cost to be born in exchange for the known reward. Thus, for example, Gneezy and Rustichini (2000) found (in a paper aptly titled "A fine is a price") that, when a fine for picking up children after the closing hour was introduced at a day care center, late pickups actually increased (c.f., Tenbrunsel and Messick, 1999). This suggests that, for legal sanctions to be most effective, they must be implemented in a way that their consequences are severe and accompanied by an implicit moral judgment. It also suggests that rewards may be used to help highlight exemplary behavior and to strengthen the professional ethic, even if those rewards are primarily symbolic, such as certificates, trophies, or awards.

\section{DISCUSSION}

Conflicts of interest have received remarkably little attention from social and behavioral scientists. Such conflicts are a logical focus for economic analysis. Yet there has been very little economic research on conflicts of interest, perhaps because economics typically assumes self-interest, which rules out the very professional and ethical motives that lead to the conflict in the first place. Some research in areas such as accounting, corporate finance, or medicine, have sought to measure the magnitude of the biases and inefficiencies caused by conflicts of interest, but even in these areas there has been little basic research addressing the psychological processes that cause people to succumb to, or resist succumbing to, conflicts of interest.

The role played by cognitive factors has been largely ignored in the academic literature on conflict of interest, which has been dominated by academics who adhere, more or less closely, to a rational choice perspective. As we have argued elsewhere (Bazerman et al., 2002), succumbing to a conflict of interest-putting one's own interests above professional responsibilities-has been viewed, in the media, by the public, and by academics, as a matter of deliberate corruption. The evidence reviewed here, however, is consistent with the conclusion from our earlier research that the violations of professionalism induced by conflicts of interest often occur automatically and without conscious awareness (see also Bargh et al., 2001).

Deterrence of misbehavior using the threat of legal punishments is a clumsy public policy tool for achieving the goal of strengthening professional norms. If our goal is to sustain moral behavior, legal penalties will never be sufficient to compel people to comply with building codes, eradicate political corruption, respect queues, pay taxes, avoid littering, or avoid cheating on tests. For the ethical principles that undergird economic and social cooperation to survive, people must internalize social values. 
While we have been critical of American culture as self-interested and individualistic, many of the social norms surrounding ethical behavior and compliance with rules are stronger in the United States than in many other cultures. Further cultivating this mindset, particularly among professionals, is one key to blunting the potentially destructive power of conflicts of interest. Inculcating these values into professional training may be the way to obtain the automaticity that is the key to the solution.

While we know relatively little about how to instill norms or about how long such a process is likely to take, the experience of recent decades has given us a wealth of insights into how rapidly prosocial professional norms can be undermined. Clearly, eliminating conflicts of interest wherever possible should be the first line of defense. Accountants should not be permitted to provide consulting services to the companies they audit. Doctors should not be permitted to accept gifts from pharmaceutical companies. And financial analysts should not be providing buy/sell recommendations about companies whose business their firms are trying to court. Reducing the incentives for bias will go a long way toward decelerating the slide down the slippery slope of dissenting professional norms. But changing these incentives is unlikely to solve the problem by itself. We need a change in societal mindset from an embracing of self-interest to a greater concern for the social good; from an automatic consideration of whether we are better off than we were four years ago to a consideration of the kind of society we are creating for our children.

\section{CLOSING COMMENT}

On May 24th, 2001, the dance floor of the Versailles wedding hall in Jerusalem collapsed during a wedding, killing 24 wedding guests and injuring hundreds. Investigations into the calamity revealed a number of building construction code violations at the wedding hall, made possible by a broader culture of sloppiness, cheating, and corruption. Israeli Prime Minister Ariel Sharon, who called the incident a national tragedy, blamed a cultural mind-set in which Israelis try to get away with as much as they can and look upon those who conscientiously follow rules as suckers. In his comments before the Israeli parliament, he referred to Israelis who return from abroad and deride Americans and Europeans for respectfully waiting in line and obeying the law. "They look on these citizens as suckers," Sharon said. "They are not the suckers. We are the suckers" (as quoted in Sontag, 2001). Recent trends, if not halted, threaten to make suckers of us all.

\section{ACKNOWLEDGMENTS}

Thanks to Sapna Shah and Kavita Shah for critical editorial comments on this paper. 


\section{REFERENCES}

Babcock, L., Loewenstein, G., Issacharoff, S., and Camerer, C. (1995). Biased judgments of fairness in bargaining. Am. Econ. Rev. 85(5): 1337-1343.

Bargh, J. A. (1989). Conditional automaticity: Varieties of automatic influence in social perception and cognition. In Uleman, J. S., and Bargh, J. A. (eds.), Unintended Thought, Guilford Press, New York, pp. 3-51.

Bargh, J. A., and Chartrand, T. L. (1999). The unbearable automaticity of being. Am. Psychol. 54(7): $462-479$.

Bargh, J. A., Gollwitzer, P. M., Lee-Chai, A., Barndollar, K., and Troetschel, R. (2001). The automated will: Nonconscious activation and pursuit of behavioral goals. J. Pers. Soc. Psychol. 81(6): 10141027.

Bazerman, M. H., Loewenstein, G., and Moore, D. A. (2002). Why good accountants do bad audits. Harvard Bus. Rev. 80(1): 87-102.

Bem, D. J. (1972). Self-perception theory. In Berkowitz, L. (ed.), Advances in Experimental Social Psychology, Vol. 6. Academic Press, New York, pp. 1-62.

Bower, G. H. (1981). Mood and memory. Am. Psychol. 36: 129-148.

Burger, W. (1984). United States v. Arthur Young and Co. (Vol. 82-687): Supreme Court of the United States.

Chaiken, S., and Trope, Y. (eds.). (1999). Dual-Process Theories in Social Psychology, Guilford Press, New York.

Chartrand, T. L., and Bargh, J. A. (1996). Automatic activation of impression formation and memorization goals: Nonconscious goal priming reproduces effects of explicit task instructions. J. Pers. Soc. Psychol. 71(3): 464-478.

Chen, S., Shechter, D., and Chaiken, S. (1996). Getting at the truth or getting along: Accuracy- versus impression-motivated heuristic and systematic processing. J. Pers. Soc. Psychol. 71(2): 262-275.

Cialdini, R. B., Borden, R. J., Thorne, A., Walker, M. R., Freeman, S., and Sloan, L. R. (1976). Basking in reflected glory: Three (football) field studies. J. Pers. Soc. Psychol. 34(3): 366-375.

Dana, J., and Loewenstein, G. (2003). A social science perspective on gifts to physicians from industry. J. Am. Med. Assoc. 290(2): 252-255.

Denes-Raj, V., and Epstein, S. (1994). Conflict between intuitive and rational processing: When people behave against their better judgment. J. Pers. Soc. Psychol. 66(5): 819-829.

Dugan, I. J., Berman, D., and Barrioneuvo, A. (2002, April 15). On camera, people at Andersen, Enron tell how close they were. Wall Street Journal, pp. 1-A.

Epstein, S. (1990). Cognitive-experiential self-theory. In Pervin, L. A. (ed.), Handbook of Personality: Theory and Research, Guilford Press, New York, pp. 165-192.

Epstein, S. (1994). Integration of the cognitive and the psychodynamic unconscious. Am. Psychol. 49(8): 709-724.

Epstein, S., Lipson, A., Holstein, C., and Huh, E. (1992). Irrational reactions to negative outcomes: Evidence for two conceptual systems. J. Pers. Soc. Psychol. 62(2): 328-339.

Frank, R., Gilovich, T., and Regan, D. (1993). Does studying economics inhibit cooperation? J. Econ. Perspect. 7: 159-171.

Frederick, S., Loewenstein, G., and O'Donoghue, T. (2002). Time discounting and time preference: A critical review. J. Econ. Literature 40(2): 351-401.

Freedman, J. L., and Fraser, S. C. (1966). Compliance without pressure: The foot-in-the-door technique. J. Pers. Soc. Psychol. 4(2): 195-202.

Gilbert, D. T., Krull, D. S., and Malone, P. S. (1990). Unbelieving the unbelievable: Some problems in the rejection of false information. J. Pers. Soc. Psychol. 59(4): 601-613.

Gilbert, D. T., Krull, D. S., and Pelham, B. W. (1988a). Of thoughts unspoken: Social inference and the self-regulation of behavior. J. Pers. Soc. Psychol. 55(5): 685-694.

Gilbert, D. T., Pelham, B. W., and Krull, D. S. (1988b). On cognitive busyness: When person perceivers meet persons perceived. J. Pers. Soc. Psychol. 54(5): 733-740.

Gilovich, T. (1991). How We Know What Isn't So: The Fallibility of Human Reason in Everyday Life, Free Press, New York.

Glover, Jonathan (2000). Humanity: A moral history of the twentieth century. Yale University Press, New Haven, CT. 
Gneezy, Uri, and Rustichini, Aldo (2000). A fine is a price. J. Leg. Stud. 29: 1-17

Gobet, F., and Simon, H. A. (1996). Recall of random and distorted chess positions: Implications for the theory of expertise. Mem. Cognit. 24(4): 493-503.

Grant, S. (2000, September 20). SEC Hearing on Auditor Independence [Web page]. Retrieved October 20, 2001, from http://www.sec.gov/rules/extra/hear0920.htm

Haidt, J. (2001). The emotional dog and its rational tail: A social intuitionist approach to moral judgment. Psychol. Rev. 108(4): 814-834.

Haney, C., Banks, C., and Zimbardo, P. (1973). Interpersonal dynamics in a simulated prison. Int. J. Criminol. Penol. 1: 69-97.

Hastie, R. (1984). Causes and effects of causal attribution. J. Pers. Soc. Psychol. 46(1): 44-56.

Hastorf, A. H., and Cantril, H. (1954). They saw a game: A case study. J. Abnorm. Soc. Psychol. 49: $129-134$.

Houston, W. (2000, April 18). Greatest Hits. Arista.

Kunda, Z. (1990). The case for motivated reasoning. Psychol. Bull. 108(3): 480-498.

Latane, B. (1981). The psychology of social impact. Am. Psychol. 36(4): 343-356.

LeDoux, J. (1996). The Emotional Brain, Simon and Schuster, New York.

Lepper, M. R. (1973). Dissonance, self-perception, and honesty in children. J. Pers. Soc. Psychol. 25(1): 65-74.

Lieberman, M. D., Gaunt, R., Gilbert, D. T., and Trope, Y. (2002). Reflexion and reflection: A social cognitive neuroscience approach to attributional inference. In Zanna, M. P. (ed.), Advances in Experimental Social Psychology, Vol. 34, Academic Press, San Diego, CA, pp. 199-249.

Lifton, R. J. (2000). The Nazi Doctors: Medical Killing and the Psychology of Genocide, Basic, New York.

Loewenstein, G., and Lerner, J. (2002). The role of emotion in decision making. In. Davidson, R. J., Goldsmith, H. H., and Scherer, K. R. (eds.), Handbook of Affective Science, Oxford University Press, Oxford, pp. 619-642.

Loewenstein, G. F., Weber, E. U., Hsee, C. K., and Welch, N. (2001). Risk as feelings. Psychol. Bull. 127(2): 267-286.

McFatter, R. M. (1982). Purposes of punishment: Effects of utilities of criminal sanctions on perceived appropriateness. J. Appl. Psychol. 67(3): 255-267.

McRoberts, F. (2002, September 1). The fall of Andersen. Chicago Tribune, pp. 1-A.

Milgram, S. (1974). Obedience to Authority, Harper and Row, New York.

Monin, B., and Miller, D. T. (2001). Moral credentials and the expression of prejudice. J. Pers. Soc. Psychol. 81(1): 33-43.

Most, S. B., Simons, D. J., Scholl, B. J., Jimenez, R., Clifford, E., and Chabris, C. F. (2001). How not to be seen: The contribution of similarity and selective ignoring to sustained inattentional blindness. Psychol. Sci. 12(1): 9-17.

Robbins, A. (1986). Unlimited Power, Fawcett Columbine, New York.

Schneider, W., and Shiffrin, R. M. (1977). Controlled and automatic human information processing: Detection, search, and attention. Psychol. Rev. 84(1): 1-66.

Schuetze, W. (1994). A mountain or a molehill? Account. Horiz. 8(1): 69-75.

Shiv, B., and Fedorikhin, A. (1999). Heart and mind in conflict: The interplay of affect and cognition in consumer decision making. J. Consum. Res. 26(3): 278-292.

Small, D. A., and Loewenstein, G. (2003). Helping $a$ victim or helping the victim: Altruism and identifiably. J. Risk Uncertainty 26: 5-16.

Sontag, D. (2001, May 31). Sharon Scolds his Nation Over Calamity. New York Times, p. A8.

Staw, B. M. (1976). Knee-deep in the Big Muddy: A study of escalating commitment to a chosen course of action. Organ. Behav. Hum. Decis. Process. 16(1): 27-44.

Staw, B. M., and Ross, J. (1989). Understanding behavior in escalation situations. Science 246(4927): 216-220.

Stock, H. (2003, February 24). Companies reported record restatements last year. Investor Relat. Bus. 1.

Tenbrunsel, A. E., and Messick, D. M. (1999). Sanctioning systems, decision frames, and cooperation. Adm. Sci. Q. 44(4): 684-707.

Thompson, L., and Loewenstein, G. (1992). Egocentric interpretations of fairness and interpersonal conflict. Organ. Behav. Hum. Decis. Process. 51(2): 176-197.

van Knippenberg, A., Dijksterhuis, A., and Vermeulen, D. (1999). Judgment and memory of a criminal act: The effects of stereotypes and cognitive load. Eur. J. Soc. Psychol. 29(2): 191-201. 